\title{
Winter anticyclonic blocking effects over Europe during 1960-2000 from an ensemble of regional climate models
}

\author{
Kleareti Tourpali ${ }^{1, *}$, Prodromos Zanis ${ }^{2}$ \\ ${ }^{1}$ Laboratory of Atmospheric Physics, Physics Department, and ${ }^{2}$ Department of Meteorology and Climatology, \\ School of Geology, Aristotle University of Thessaloniki, Thessaloniki, Greece
}

\begin{abstract}
Anticyclonic blocking is an important factor for mid-latitude climate variability and is considered to play a key role in anomalous and extreme events. In this study we present an analysis of atmospheric blocking events on the output of a multi-model ensemble of regional climate model (RCM) simulations. The ensemble consists of a set of 13 RCMs, nested in the European domain with a resolution of $50 \times 50 \mathrm{~km}$. All RCM simulations were driven by similar lateral boundary conditions, namely, the ERA-40 reanalysis for the period 1961-2000, as part of the European project ENSEMBLES. The aim was to investigate the ability of the different RCMs to reproduce the anticyclonic blocking events of the forcing reanalysis fields. When the atmospheric blocking events were examined in terms of their frequency in the RCM outputs, we found that the longitudinal dependence of the frequency in ERA-40 is reproduced by all RCMs. The composite map of the $500 \mathrm{hPa}$ geopotential height for the days central to blocking episodes calculated for the RCM ensemble was found to be similar in pattern and magnitude to the respective composite map from ERA-40 reanalysis. Related effects of the blocking events on daily average temperature and precipitation were studied in the RCM simulations and compared with respective observational (E-OBS) and reanalysis (ERA-40) gridded data sets. The results of this process-oriented evaluation study indicated a rather good ability of the different RCMs to reproduce the anticyclonic blocking events of the forcing reanalysis, as well as their influence on temperature and precipitation anomalies.
\end{abstract}

KEY WORDS: Blocking anticyclones $\cdot$ Regional climate models $\cdot$ Europe

\section{INTRODUCTION}

A satisfactory representation of the weather systems is essential for the accurate modelling of the mid-latitude climate, as well as for the provision of credible projections in climate change scenarios. Blocking situations have attracted scientific interest for several decades in the meteorological literature. Blocking conditions refer to those weather situations in which the prevailing westerly circumpolar flow in the extratropics is temporarily disrupted in a sector by strong persistent meridional type flow through the presence of strong slow-moving or stationary anticyclones that persist for multiple days to weeks (Austin
1980, Treidl et al. 1981). Blocking anticyclones have a vertical extent that blocks the jet stream, preventing it from following its climatological path. These structures have a tendency to occur in jet-exit regions, with increased blocking frequency over the northeastern Atlantic and the western United States (Pelly \& Hoskins 2003, Tyrlis \& Hoskins 2008a). A wide range of climatological studies of blocking events, based on both subjective and objective definitions of blocking, have revealed that the blocking occurrence in these regions seriously affects European weather and climate (Rex 1950, Dole \& Gordon 1983, Knox \& Hay 1985, Tibaldi et al. 1994, Lupo \& Smith 1995, Diao et al. 2006). 
Since a single blocking episode can persist for weeks, it is possible that a few blocking episodes can determine the climate characteristics of one winter, thus leading to substantial changes in regional climates (Stein 2000). Furthermore, the predictability of the climate for a region is considered to be higher when and where blocking occurs (Tibaldi \& Molteni 1990). As a consequence, in recent years atmospheric blocking has been a frequent topic in studies of numerical weather prediction models (Tibaldi \& Molteni 1990, Anderson 1993, Tibaldi et al. 1994) and global circulation models (GCMs; Sausen et al. 1995, Tibaldi et al. 1997, D'Andrea et al. 1998). A common finding is a generalized underestimation of the observed blocking frequency and persistence (Tibaldi \& Molteni 1990, Anderson 1993, Tibaldi et al. 1994, 1997, Scaife et al. 2010). In recent years, realizations with ensembles of members that take into account some uncertainties in initial conditions and in model formulation have improved the simulation of atmospheric blocking in the context of medium range weather forecasting (Watson \& Colucci 2002, Pelly \& Hoskins 2003), whereas GCM simulations have only shown modest improvements (D'Andrea et al. 1998, Randall et al. 2007, Vial \& Osborn, 2012). Low spatial resolution or problems in the model formulation of certain physical parameterizations (usually related to small-scale processes) have been widely acknowledged as important limiting factors towards a proper simulation of important extratropical weather systems (Tibaldi et al. 1997), including blocking. Some studies suggest that it is likely that limited horizontal or vertical resolution in current GCMs contributes to their lack of blocking (Scaife \& Knight 2008, Matsueda et al. 2009, Jung et al. 2012), although there are studies with controversial results on this issue (Woollings et al. 2010). However, other recent studies suggest that blocking frequency errors are also largely attributable to the large-scale climatological bias of the model (Scaife et al. 2010, Scaife et al. 2011) with these 2 above-mentioned views not being necessarily in conflict.

Regional climate models (RCMs) have been developed for the application of dynamical downscaling methods to enhance the regional information provided by GCMs (or by the large-scale reanalysis fields) at resolutions commonly between 50 and 10 $\mathrm{km}$ (Giorgi et al. 1990). RCMs represent in more detail surface features, such as complex mountain topographies, coastlines, small islands, lakes and peninsulas, and hence they have the ability to simulate atmospheric processes at a wide range of spatial and temporal scales.
When comparing the RCMs with their driving GCM, they generally reproduce the large-scale circulation of the GCM, though in some cases there are substantial differences between regional biases in surface temperature and precipitation (Jacob et al. 2007). For the RCMs, the lateral forcing by the GCMs or reanalysis introduces a source of uncertainty. Even forced with the same lateral boundary conditions (LBCs), RCMs may simulate different atmospheric circulation patterns within the domain (Giorgi \& Bi 2000, Christensen et al. 2001). This is the so-called internal variability of RCMs, which results from chaotic processes intrinsic to the atmosphere and corresponds to the irreproducible component of climate variability in a multi-member ensemble simulation. The issue of internal variability has been increasingly investigated in recent years, especially within the regional climate modeling community, and it has been shown to vary according with the considered geophysical variable (Alexandru et al. 2007), synoptic conditions (Lucas-Picher et al. 2008), season (Caya \& Biner 2004), domain size (Leduc \& Laprise 2009), location (Rinke et al. 2004) and physical mechanism (Crétat \& Pohl 2012).

In this study we present an analysis of atmospheric blocking events on the output of a multimodel ensemble of RCM simulations, all forced by similar LBCs, namely the ERA-40 reanalysis for the period 1961-2000, as part of the European project ENSEMBLES. The aim is to investigate the ability of the different RCMs to reproduce the anticyclonic blocking events of the forcing reanalysis fields, which can be considered as a process-oriented evaluation study. Our analysis is focused on winter, which is the season with the highest meteorological variability during the year.

Previous studies have shown a good performance of the RCMs that participated in ENSEMBLES when forced by ERA-40 meteorological fields. For example, Sanchez-Gomez et al. (2009) analyzed the ability of an ensemble of $13 \mathrm{RCMs}$ forced by ERA-40 data to reproduce weather regimes over the EuropeanAtlantic sector during the period 1961-2000. They concluded that the RCMs reproduced reasonably well the weather regimes' behavior in terms of composite pattern, mean frequency of occurrence and persistence. Furthermore, in another recent study based on 9 RCMs forced by ERA-40 fields it was shown that these models represented fairly well the seasonal mean spatial pattern and amount of precipitation over Europe at both 25 and $50 \mathrm{~km}$ horizontal grid spacing (Rauscher et al. 2010). 
Table 1. Main features of the regional climate models (RCMs) used in this study

\begin{tabular}{|lll|}
\hline Institute & \multicolumn{1}{c|}{ RCM } & \multicolumn{1}{c}{ Source } \\
\hline CHMI & ALLADIN & Radu et al. (2008) \\
CNRM & ALLADIN & Farda et al. (2007) \\
DMI & HIRHAM & Christensen et al. (1996) \\
ETHZ & CLM & Böhm et al. (2006) \\
GKSS & CLM & Böhm et al. (2006) \\
ICTP & RegCM & Giorgi \& Mearns (1999) \\
KNMI & RACMO & van Meijgaard et al. (2008) \\
METNO & HIRHAM & Haugen \& Haakensatd (2006) \\
HADM (METOHC) & HadRM3 & Collins et al. (2006) \\
MPI & REMO & Jacob (2001) \\
SMHI & RCA & Kjellström et al. (2005) \\
OURANOS & CRCM & Plummer et al. (2006) \\
UCLM & PROMES & Sanchez et al. (2004) \\
\hline
\end{tabular}

\section{DATA AND METHODS}

In this study we use data from 13 RCM simulations for the period 1961-2000, all forced by ERA-40. The data come from the EU-FP6 ENSEMBLES project, and a summary of the models and their characteristics is shown in Table 1 (see also the ENSEMBLES project online http://ensemblesrt3. dmi.dk). Within this project, 2 sets of experiments with horizontal resolution of 25 and $50 \mathrm{~km}$ over the same area were produced. Here we use only the $50 \mathrm{~km}$ resolution experiment results, and in particular the $500 \mathrm{hPa}$ (Z500) geopotential height fields, the surface temperature and the surface precipitation fields. In order to identify the atmospheric blocking anticyclones in the forcing field we have used the daily average $500 \mathrm{hPa}$ geopotential height fields from the ERA-40 reanalysis (Uppala et al. 2005), in the $1.125 \times 1.125^{\circ}$ full grid resolution.

In this study, we analyse the climatic effects of the European blocking episodes as depicted in RCMs, and compare them with observations. For this purpose, we use the E-OBS analysis, a daily gridded observational data set for precipitation, temperature and sea level pressure in Europe, originally developed as part of the ENSEMBLES project. The full data set covers the period 01 January 1950 to 30 June 2011. Temperature and precipitation data are at a 0.5 degree resolution (Haylock et al. 2008)

All of the analyses presented in the following sections have been performed for the domain of the RCMs, nested over Europe and part of the North Atlantic. We used the ENSEMBLES common minimum area of the RCMs (see also Fig. 1 in Sanchez-Gomez et al. 2009). The ERA-40 data analysis was also per- formed over the same area. The detection of atmospheric blocking events has been the subject of many studies in the past, and a number of indices have been proposed. The $500 \mathrm{hPa}$ geopotential height (Z500) is the most widely used base field (e.g. Dole \& Gordon 1983, Tibaldi \& Molteni 1990, Trigo et al. 2004, Barriopedro et al. 2006). In recent years, blocking indices based on the potential vorticity (PV) field were proposed and used in a number of studies. For example, Schwierz et al. (2004) recently introduced a quasi-3-dimensional dynamically based index for identifying a block, which was motivated by the fact that it captures the core PV anomaly of the block at the tropopause region and can thereby provide further insight on the dynamical evolution and maintenance of blocks (Croci-Maspoli et al. 2007). Some other recent blocking indices have stressed the importance of using potential temperature $(\theta)$ on the dynamical tropopause (2 potential vorticity unit [PVU] isosurface [1 PVU $=10^{-6} \mathrm{~m}^{2} \mathrm{~s}^{-1} \mathrm{~K}$ $\mathrm{kg}^{-1}$ ]) (Pelly \& Hoskins 2003, Berrisford et al. 2007, Tyrlis \& Hoskins 2008a,b). While this field may have a more dynamically meaningful interpretation in the blocking anticyclone framework, the results of Barnes et al. (2012) showed that seasonal blocking climatologies are very similar between the Z500 and $\theta 2$ indices when the same blocking regime method is applied.

In our case, the availability of the RCM fields allows us to work only with the geopotential height definition of blocking anticyclones. The procedure described below has been followed for the Z500 fields derived from the ERA-40 reanalysis, as well as the equivalent fields from the 13 RCMs used here, so that we can first compare the ability of the RCMs to reproduce wintertime blocking over the European sector. The Z500 fields from the RCMs were linearly interpolated to a $1.125^{\circ} \times 1.25^{\circ}$ field to allow direct comparison with the ERA-40 results.

Using a procedure similar to that of Trigo et al. (2004), we computed the $500 \mathrm{hPa}[\mathrm{z}(\lambda, \varphi)]$ geopotential height gradients GHGS and GHGN for the $1.125^{\circ}$ longitude intervals as:

GHGS $=\frac{z\left(\lambda, \varphi_{0}\right)-z\left(\lambda, \varphi_{s}\right)}{\varphi_{o}-\varphi_{s}} \quad$ and $\quad$ GHGN $=\frac{z\left(\lambda, \varphi_{n}\right)-z\left(\lambda, \varphi_{o}\right)}{\varphi_{n}-\varphi_{o}}$ where $z(\lambda, \varphi)$ is the geopotential height at latitude $\varphi$ and longitude $\lambda$. The latitudes $\varphi_{0}, \varphi_{\mathrm{n}}$ and $\varphi_{\mathrm{s}}$ are defined as $\varphi_{\mathrm{o}}=51.750^{\circ} \mathrm{N}+\Delta, \varphi_{\mathrm{n}}=66.375^{\circ} \mathrm{N}+\Delta$ and 
$\varphi_{\mathrm{s}}=36.000^{\circ} \mathrm{N}+\Delta$, with $\Delta=-3.375,0$, and $3.375^{\circ}$, respectively. A given longitude is then defined as blocked if both conditions GHGS > 0 and GHGN < $-10 \mathrm{~m} \mathrm{deg}^{-1}$ latitude are satisfied for at least one of the $\Delta$ values, and at the same time the geopotential height anomaly at the central latitude $\varphi_{\mathrm{o}}$ is positive, so that $\left(z\left(\lambda, \varphi_{0}\right)-\overline{z\left(\lambda, \varphi_{0}\right)}\right)>0$ (Barriopedro et al. 2006).

A sector is assumed to be blocked if 3 or more adjusted latitudes are blocked, and a blocking episode is defined when blocking occurs for $\geq 5$ consequent days. Blocking episodes were computed for every month of the $40 \mathrm{yr}$ period, but in this analysis we present results for the winter period (December through February) from 1961 to 2000. Note that due to the restrictions imposed by the common domain of the RCMs used here, our choice of latitudes $\varphi_{0}, \varphi_{n}$ and $\varphi_{\mathrm{s}}$ is limited to the south of the area commonly used in defining blocking episodes (e.g. Tibaldi \& Molteni 1990, Pelly \& Hoskins 2003).

Anomalies of the daily average temperature and precipitation fields were calculated by subtracting from each daily field the long-term daily mean calculated from the $40 \mathrm{yr}$ simulations of the RCMs, smoothed by a $31 \mathrm{~d}$ running mean filter. The same procedure was followed to calculate the daily anomalies of the surface temperature and precipitation fields from the observations of the E-OBS gridded data set, as well as the ERA-40 reanalysis in the full resolution of $1.125^{\circ} \times 1.125^{\circ}$. Here we use the anomaly fields for the winter period, i.e. from December through February. A composite map analysis of the anomalies in temperature and precipitation fields associated with the presence of a blocking over the European sector is presented in the next section. These composite maps were constructed for the temperature and precipitation fields of each RCM and for the equivalent fields of the E-OBS observations and ERA-40. In order to capture the effects of the blocking anticyclone at its full development, when it expands over the area between $5^{\circ} \mathrm{W}$ and $12.5^{\circ} \mathrm{E}$ (where the largest frequency of blocking occurs, as shown in the next section) and before it starts to dissolve, we use as key dates only the central dates of the blocking episodes calculated from ERA-40 (in total 68 cases). As central date we consider the date that is central to the episode duration (e.g. for an episode that is formed in the area between $5^{\circ} \mathrm{W}-$ $12.5^{\circ} \mathrm{E}$ and lasts $5 \mathrm{~d}$, as a central date we consider the third day from the onset of the episode).

\section{RESULTS AND DISCUSSION}

Fig. 1 presents the blocking frequency in the winter months calculated for the ERA-40 and RCMs. Only days belonging to blocking episodes lasting at least $5 \mathrm{~d}$ were taken into account. Our computations reveal that blocking, and in particular blocking episodes of $>5$ consequent days, was reproduced by all RCMs. All models show that the largest number of blocking episodes occurs in the region between $2.5^{\circ}$ and $7.5^{\circ} \mathrm{E}$, the same as in the ERA-40 data set. This region of highest frequency of occurrence, as well as the general shape of the response in the EuroAtlantic sector that we examine here, is the same as the one calculated if the classic definition of TM90 is used (e.g. Tibaldi \& Molteni 1990, D'Andrea et al. 1998, Trigo et al. 2004, Barriopedro et al. 2006). The number of blocking days drops in both ERA-40 and the RCMs as we move further to the east or to the west of this sector. All RCMs underestimate the blocking frequency at $7.5^{\circ} \mathrm{W}$ when compared with ERA-40, presumably due to the proximity of this area to the western lateral boundaries of the RCMs domain, which is the inflow area of the domain. Among the 13 RCMs, the KNMI, ETHZ, GKSS and CHMI RCMs are closer to the ERA-40 blocking frequencies, while other models set the upper and lower levels of the range, with CNRM and MPI showing a slight

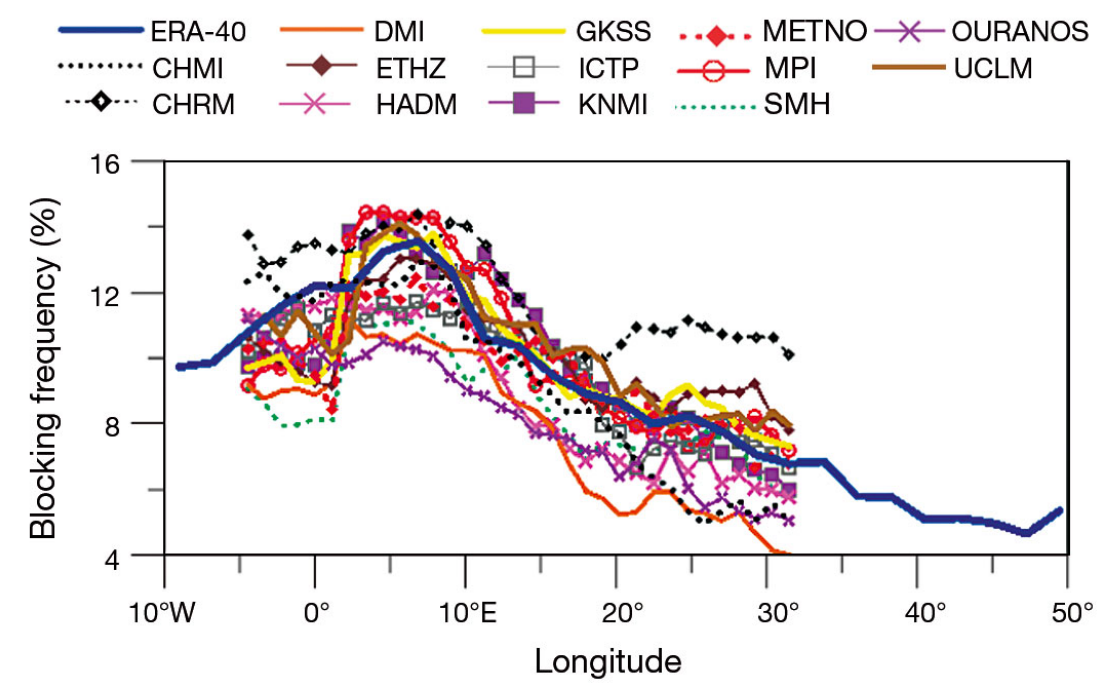

Fig. 1. Blocking frequency for the winter (December through February) as depicted in ERA-40 (thick blue line) and regional climate model simulations. Model names and corresponding lines are included 
overestimation and SMHI, DMI and OURANOS underestimating the frequency of blocking events in general, a feature that is partly due to the definition of the blocking episode and the duration criterion.

A common finding in GCM studies is a generalized underestimation of the observed blocking frequency and persistence (Tibaldi \& Molteni 1990, Anderson 1993, Tibaldi et al. 1994, 1997, Vial \& Osborn 2012). Interestingly, our study shows also a tendency for underestimation in the frequency of blocking events in the majority of RCMs, despite the RCM higher resolution and the fact that the simulations used here employ ERA-40 reanalysis as LBCs. Nevertheless, an additional error source for GCM data analysis (and most probably applicable also to RCM analysis), as discussed by Barriopedro et al. (2010), may arise when automatic algorithms are applied to GCM output data without an adequate adaptation of the blocking detection method to the climate of the model. This issue could be partially addressed in a future study with the use of a bi-dimensional blocking index describing the 2-dimensional evolution of blocking events in the RCM outputs, as was also pointed by Diao et al. (2006).

The composite anomalies of the geopotential heights for the dates central to blocking episodes defined in the Materials and Methods are presented in Fig. 2. The left panel shows the characteristic anticyclonic pattern response of the Z500 anomalies to atmospheric blockings, as calculated from the ERA40 data (in the full resolution $1.125^{\circ} \times 1.125^{\circ}$ ), with the maximum positive difference centered over the
British Isles and the negative over Iberia and west Mediterranean. The location of the maximum is slightly different than in Trigo et al. (2004), due to differences in data sets and key dates used. The right panel shows the ensemble mean anomaly of the Z500, calculated from the geopotential height anomalies response from the $13 \mathrm{RCMs}$. Although the maximum anomaly is not as high as in the ERA-40 data, the locations of the maximum and the minimum response are the same, as has been also shown by Sanchez-Gomez et al. (2009), who used different methodology and comparison with only one single model. The $500 \mathrm{hPa}$ geopotential height fields (not shown) present the characteristics of the tropospheric circulation changes during European blocking episodes for both the ERA- 40 and the model ensemble average composites.

Fig. 3 presents the composite map of anomalies of surface temperature calculated from the E-OBS data set, from the ERA-40 reanalysis, along with the corresponding field of the multi-model ensemble mean of the RCM simulations under blocking conditions and the standard deviation of this ensemble mean. Generally, both observations and the ensemble mean of the RCM simulations show a similar dipole pattern of anomalies with positive temperature anomalies north of about $50^{\circ} \mathrm{N}$ and negative anomalies south of $50^{\circ} \mathrm{N}$. Specifically, the analysis of the anomalies in observations (Fig. 3A) reveals pronounced cold anomalies (on average about $-3^{\circ} \mathrm{C}$ ) over central Europe, at latitudes lower than $50^{\circ} \mathrm{N}$. The coldest area (about $-4^{\circ} \mathrm{C}$ ) is found over western France,
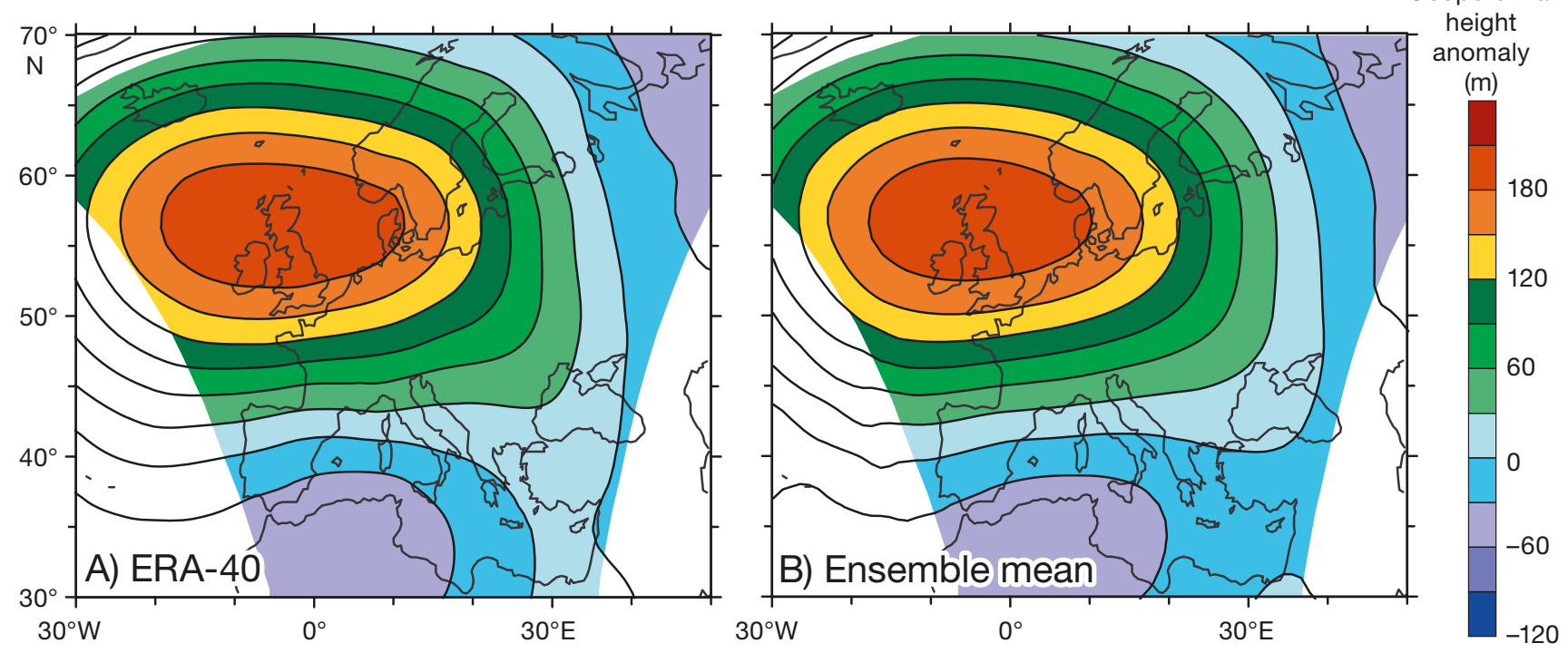

Fig. 2. Composite map of the $500 \mathrm{hPa}$ geopotential height anomalies for the days central to blocking episodes calculated for (A) the ERA-40 reanalysis (full resolution) and (B) the RCM ensemble mean 

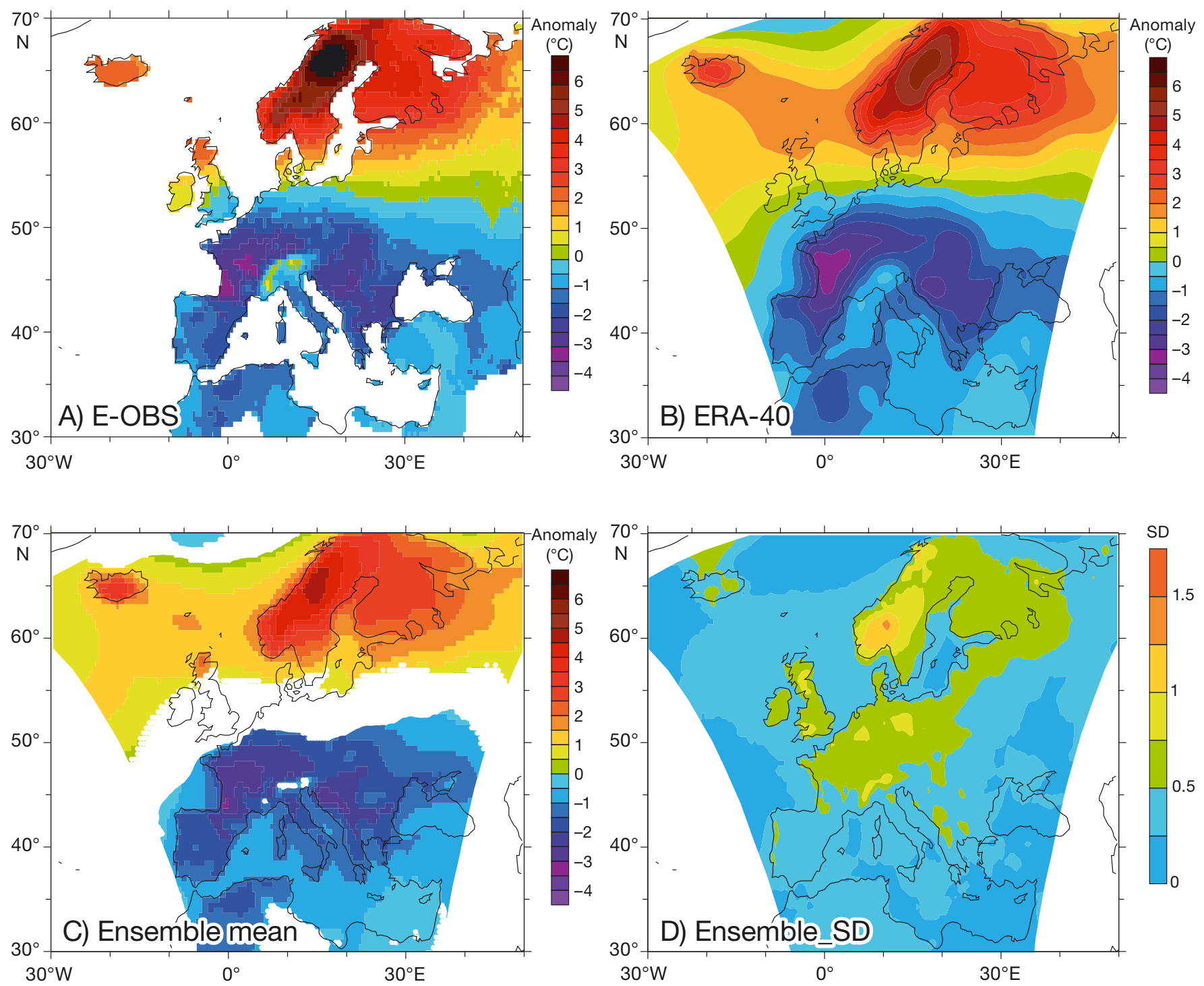

Fig. 3. Surface temperature anomalies during blocking events $\left(\right.$ in $\left.{ }^{\circ} \mathrm{C}\right)$. (A,B) Composite map of anomalies calculated from (A) the E-OBS data set and (B) the ERA-40 reanalysis. The white pattern overlay denotes areas with anomalies not significant above the $95 \%$ level. (C) The RCM ensemble response to surface temperature anomalies. Areas where the multi-model ensemble mean divided by the multi-model standard deviation (SD) is $<2.0$ (in magnitude) are left blank. (D) SD of the ensemble mean

while the northern part of the Balkan Peninsula experiences low temperatures. Low temperatures of about the same magnitude are also seen over Greece. The E-OBS data for blocking conditions over Scandinavia and Iceland show temperatures above average, the highest positive anomaly reaching $\sim 6^{\circ} \mathrm{C}$ in the area of Norway/Sweden. Over the British Isles, a gradient in surface temperature response is found, with low temperatures in south gradually increasing towards the north. It is worth noting that the anomalies shown in Fig. 3, which exceed $\pm 1.5^{\circ} \mathrm{C}$ (i.e. positive or negative), are significant above the $95 \%$ confidence level, as was found by performing a $t$-test of the difference between the composite mean anomalies during blocked days and the composite mean anomalies of winter days where no blocked longitude was present over the European-Atlantic region. In contrast, anomalies in the transition area between $50^{\circ}$ and $60^{\circ} \mathrm{N}$ in northeast Europe and Russia were not found to be statistically significant at $95 \%$, and hence are indicated with the white overlay pattern in Fig. 3. The pattern of the ERA-40 temperature anomalies (Fig. 3B) under blocking conditions resembles the respective E-OBS temperature anomalies in spatial pattern and magnitude. Nevertheless, it should be noted that there is a slight underestimation of 

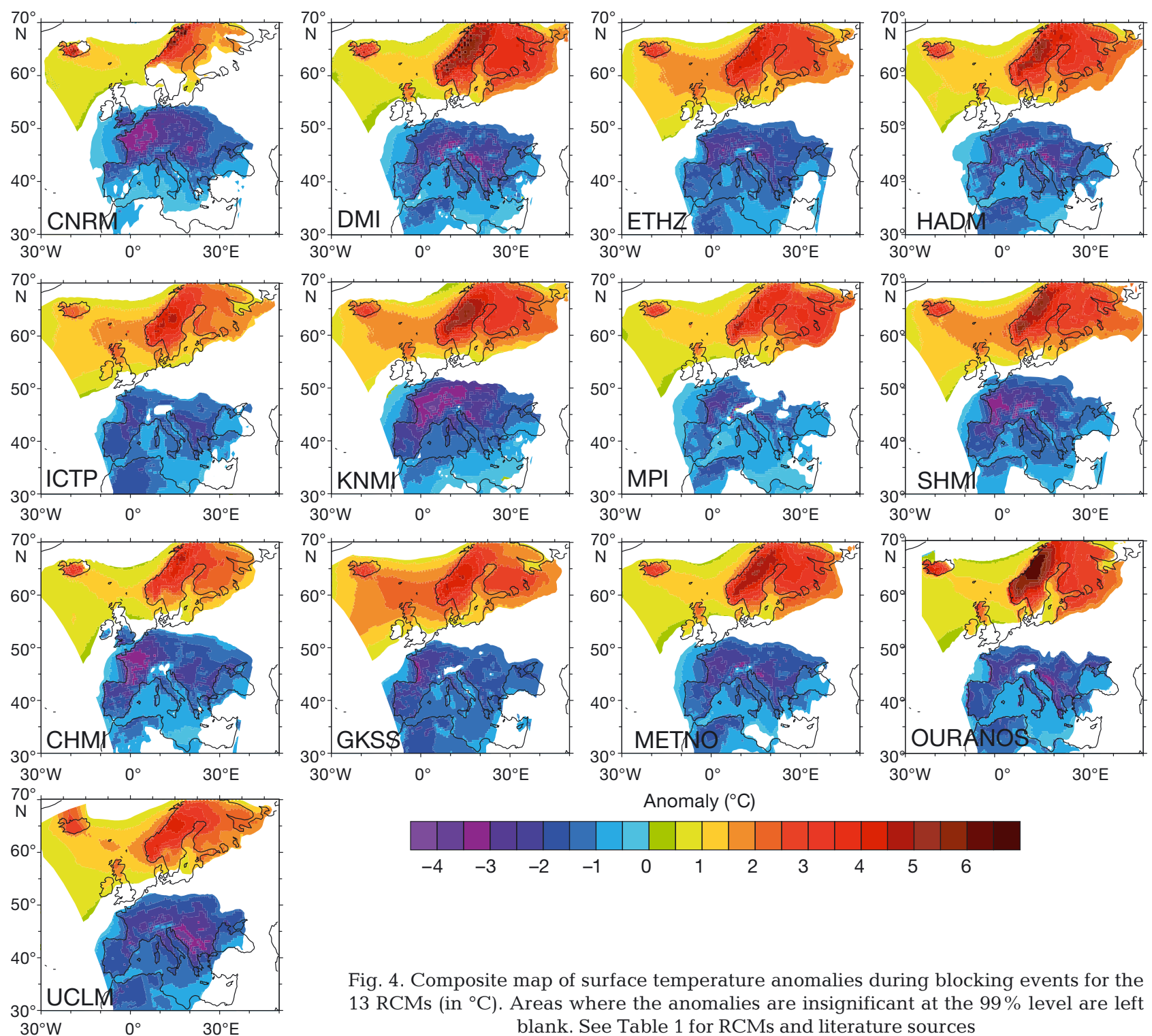

Fig. 4. Composite map of surface temperature anomalies during blocking events for the $13 \mathrm{RCMs}\left(\right.$ in ${ }^{\circ} \mathrm{C}$ ). Areas where the anomalies are insignificant at the $99 \%$ level are left blank. See Table 1 for RCMs and literature sources

about $1-2^{\circ} \mathrm{C}$ in ERA-40 temperature anomalies over central Scandinavia when compared with E-OBS temperature anomalies.

The ensemble mean of the 13 RCMs (Fig. 3C), which was calculated as the average of all models' results after transferring them into the same grid as the observations $\left(0.5^{\circ} \times 0.5^{\circ}\right)$, shows a similar magnitude and pattern of negative and positive anomalies when compared with the observations. Areas where the multi-model ensemble mean divided by the multi-model standard deviation is $<2.0$ (in magnitude) have been left blank. The standard deviation of the multi-model ensemble is presented in Fig. 3D. The largest standard deviations are found over southern Sweden and in locations over Germany and the Alpine region, where the anomaly signal between the models shows the largest deviations. It should be noted, however, that the largest standard deviation over southern Sweden does not coincide geographically with the highest positive temperature anomaly of the ensemble mean over central Scandinavia. Fig. 4 presents the surface temperature anomalies calculated from the simulations of all RCMs used in this study. The pattern of response for each individual RCM is similar to that of the E-OBS data, the ERA-40 reanalysis data and the multi-model ensemble mean. This similarity in the pattern of temperature response depicts the ability of each individual RCM to reproduce the magnitude and the pattern of the temperature anomalies under blocking condi- 

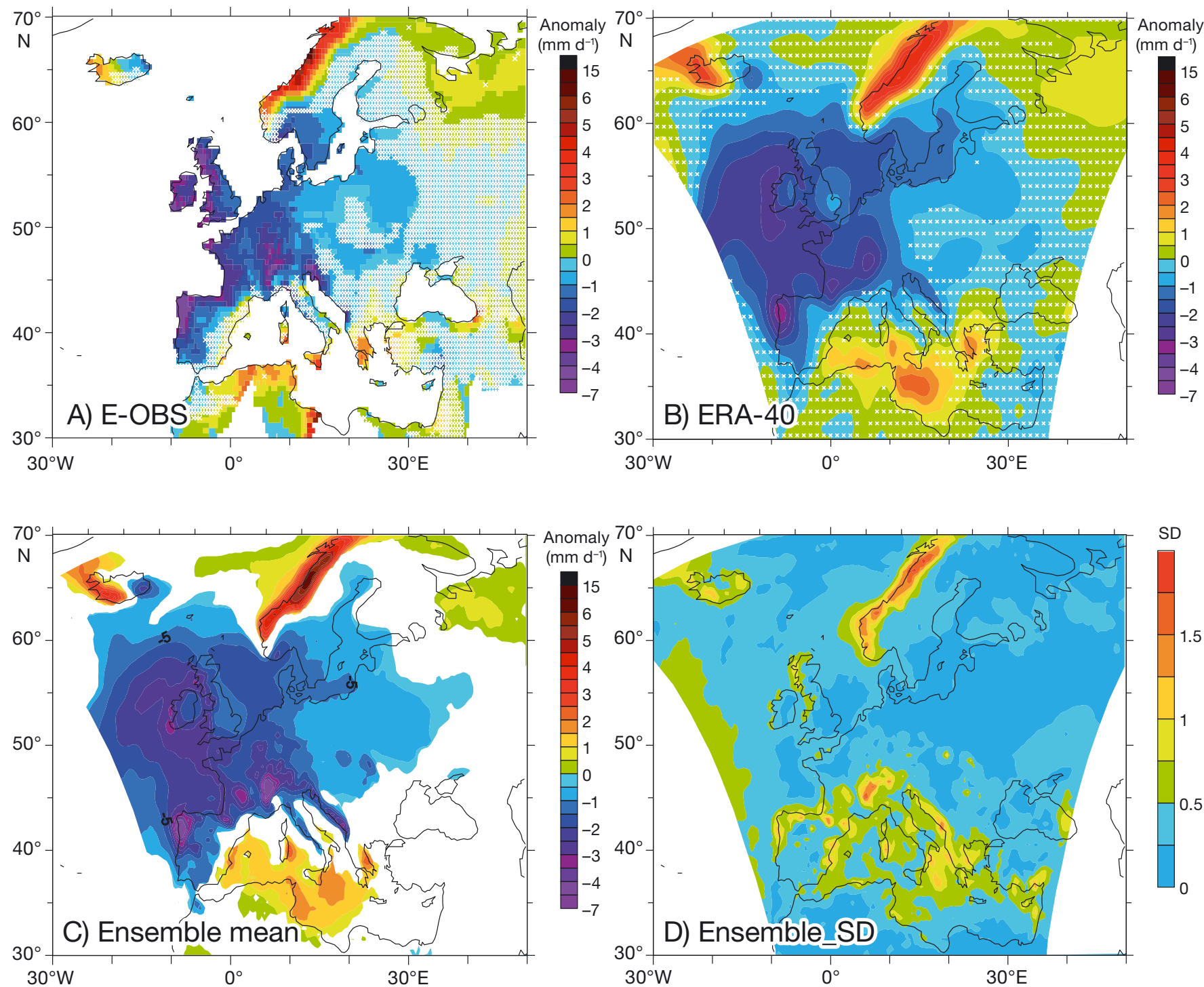

Fig. 5. Surface precipitation anomalies during blocking events. (A,B) Composite map of anomalies calculated from (A) the EOBS data set and the (B) ERA-40 reanalysis. The white pattern overlay denotes areas with anomalies not significant above the $95 \%$ level. (C) The RCM ensemble response. Areas where the multi-model ensemble mean divided by the multi-model standard deviation (SD) is $<2.0$ (in magnitude) are left blank. (D) SD of the ensemble mean

tions. Anomalies of the same sign are seen in all models, and over the same regions, even though the absolute temperature response differs slightly from model to model, as seen, for example, at the area of the largest temperature decrease over France.

The overall map of anomalies, both in the observations and the models, agrees well with findings reported previously (e.g. Rex 1950, Trigo et al. 2004). In summary, the large-scale mean temperature anomalies can be mostly explained by advective heat transport by the corresponding anomalous mean atmospheric flow. However, Trigo et al. (2004) highlighted the importance of another process, namely, the modulation by anomalous cloud cover (associated with anomalous atmospheric circulation) of the radiative transfer of heat to and from the Earth's surface. These radiative and cloud cover influences, under blocking regimes, result in the generation of different day-time and night-time temperature anomalies.

The composite maps of anomalies in precipitation are shown in Figs. 5 and 6. Specifically, in analogy to the temperature anomalies of Fig. 3, Fig. 5 presents the composite map of precipitation anomalies calculated from the E-OBS data set, from the ERA-40 reanalysis, along with the corresponding field of the multi-model ensemble mean of the RCM simulations 

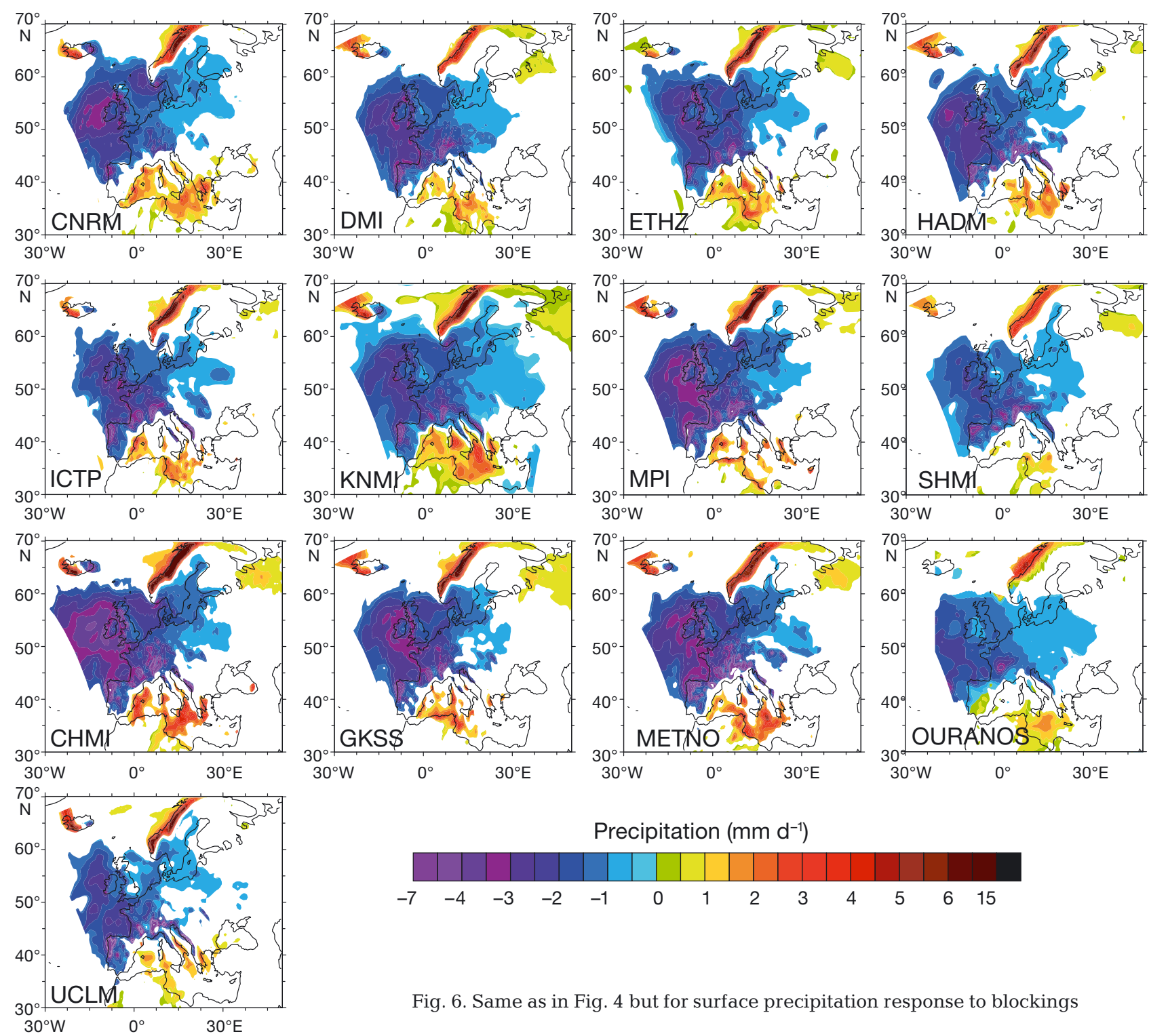

Fig. 6. Same as in Fig. 4 but for surface precipitation response to blockings

under blocking conditions and the standard deviation of this ensemble mean. In Fig. 5, where the E-OBS anomalies are presented, we see that the whole region of northwestern and central Europe is under a negative precipitation anomaly field with the driest areas found over England and NW France. This area coincides with the region covered by the anticyclonic blocking and the associated anomalies in the flow, with cold and dry air in the region. Norway, in contrast, has large positive precipitation anomalies, the same as the whole of the Mediterranean, Greece included. The same pattern of precipitation anomalies is also depicted in the ERA-40 data as well as in the ensemble mean of the RCMs. The largest standard deviations of precipitation anomalies (Fig. 5D) coincide geographically with the largest precipitation anomalies of the ensemble mean (Fig. 5C).

Fig. 6 illustrates the precipitation anomalies calculated for each individual RCM used in this study under blocking conditions. It can be clearly noted that the pattern of response for each individual RCM is similar to that of the E-OBS data, the ERA-40 reanalysis data and the multi-model ensemble mean, even though there are regional differences in the magnitude of the anomaly from one model to the other. The RCMs show that the area with the largest negative anomalies is located over the British Isles and France, and the areas located in the northern and southern parts of the blocking system show positive precipitation anomalies, and thus more rain than the average. Overall, the similarity in the pat- 
tern of precipitation response depicts the ability of each individual RCM to reproduce the magnitude and the pattern of the precipitation anomalies under blocking conditions.

\section{CONCLUSIONS}

In this study we present an analysis of atmospheric blocking events based on the output of a multi-model ensemble of 13 RCM simulations, all forced by similar LBCs - namely the ERA-40 reanalysis for the period 1961-2000 - as part of the European project ENSEMBLES. The aim of this process-oriented evaluation study was to investigate the ability of the different RCMs to reproduce (1) the frequency of anticyclonic blocking events of the forcing reanalysis and (2) the temperature and precipitation anomalies related to the blocking episodes in comparison with observations (E-OBS gridded data set and the fullresolution ERA-40 reanalysis). The detection of atmospheric blocking was based on the $500 \mathrm{hPa}$ geopotential height fields using a procedure similar to that of Trigo et al. (2004), but only days belonging to blocking episodes lasting at least $5 \mathrm{~d}$ were taken into account.

Our computations revealed that the longitudinal dependence of the frequency of the selected blocking episodes in ERA-40 was reproduced by all RCMs. Specifically, all RCMs showed that the largest number of blocking episodes occurs in the region between $2.5^{\circ} \mathrm{E}$ and $7.5^{\circ} \mathrm{E}$, while it fades out as we move further to the east or to the west, similarly to the ERA40 data set. All RCMs underestimate the blocking frequency at $7.5^{\circ} \mathrm{W}$ when compared with ERA-40, presumably due to the proximity of this area to the western lateral boundaries of the RCM domain. The composite map of the $500 \mathrm{hPa}$ geopotential height for the days central to blocking episodes calculated for the RCM ensemble was similar in pattern and magnitude to the respective composite map in the ERA-40 reanalysis.

Furthermore, the observed pattern of response of surface temperature and precipitation anomalies for the blocking episodes was also reproduced by all RCMs, even though the absolute magnitude of the response, and the area of the largest response, differ slightly from model to model. Our process-oriented evaluation study conclusively indicated the effectiveness with which the different RCMs reproduce the anticyclonic blocking events of the forcing reanalysis, as well as the influence of these blocking events on temperature and precipitation anomalies.
Acknowledgements. This work was funded by the European Community's Sixth Framework Programme as part of the project CECILIA (Central and Eastern Europe Climate Change Impact and Vulnerability Assessment) under contract no. 037005. We acknowledge the RCM and E-OBS data sets from the EU-FP6 project ENSEMBLES (http://ensembles-eu.metoffice.com) and the data providers in the ECA\&D project (http://eca.knmi.nl).

\section{LITERATURE CITED}

Alexandru A, de Elía R, Laprise R (2007) Internal variability in regional climate downscaling at the seasonal time scale. Mon Weather Rev 135:3221-3238

Anderson JL (1993) The climatology of blocking in a numerical forecast model. J Clim 6:1041-1056

Austin JF (1980) The blocking of middle latitude westerly winds by planetary waves. QJR Meteorol Soc 106: 327-350

Barnes EA, Slingo J, Woollings T (2012) A methodology for the comparison of blocking climatologies across indices, models and climate scenarios. Clim Dyn 38:2467-2481

- Barriopedro D, Garcia-Herrera R, Lupo AR, Hernandez E (2006) A climatology of Northern Hemisphere blocking. J Clim 19:1042-1063

> Barriopedro D, García-Herrera R, González-Rouco JF, Trigo RM (2010) Application of blocking diagnosis methods to general circulation models. II. Model simulations. Clim Dyn 35:1393-1409

Berrisford P, Hoskins BJ, Tyrlis E (2007) Blocking and Rossby wave breaking on the dynamical tropopause in the Southern Hemisphere. J Atmos Sci 64:2881-2898

Böhm U, Kücken M, Ahrens W, Block A and others (2006) CLM - the climate version of LM: brief description and long-term applications. COSMO Newsletter 6:225-235

Caya D, Biner S (2004) Internal variability of RCM simulations over an annual cycle. Clim Dyn 22:33-46

Christensen JH, Christensen OB, Lopez P, van Meijgaard E, Botzet M (1996) The HIRHAM4 regional atmospheric climate model. Scientific report DMI, Copenhagen, Report 96-4

> Christensen OB, Gaertner MA, Prego JA, Polcher J (2001) Internal variability of regional climate models. Clim Dyn $17: 875-887$

Collins M, Booth BBB, Harris GR, Murphy JM, Sexton DMH, Webb MJ (2006) Towards quantifying uncertainty in transient climate change. Clim Dyn 27:127-147

> Crétat J, Pohl B (2012) How physical parameterizations can modulate internal variability in a regional climate model. J Atmos Sci 69:714-724

> Croci-Maspoli M, Schwierz C, Davies HC (2007) A multifaceted climatology of atmospheric blocking and its recent linear trend. J Clim 20:633-649

Diao Y, Li J, Luo D (2006) A new blocking index and its application: blocking action in the northern hemisphere. J Clim 19:4819-4839

$>$ D'Andrea F, Tibaldi S, Blackburn M, Boer G and others (1998) Northern Hemisphere atmospheric blocking as simulated by 15 atmospheric general circulation models in the period 1979-1988. Clim Dyn 14:385-407

> Dole RM, Gordon ND (1983) Persistent anomalies of the extratropical northern hemisphere wintertime circulation: geographical distribution and regional persistence characteristics. Mon Weather Rev 111:1567-1586

Farda A, Stepanek P, Halenka T, Skalak P, Belda M (2007) Model ALADIN in climate mode forced with ERA-40 reanalysis (coarse resolution experiment). Meteorol J 10: $123-130$ 
Giorgi F, Bi X (2000) A study of internal variability of a regional climate model. J Geophys Res 105:29503-29521

Giorgi F, Mearns LO (1999) Introduction to special section: regional climate modeling revisited. J Geophys Res 104: 6335-6352

Giorgi F, Marinucci MR, Visconti G (1990) Use of a limitedarea model nested in a general circulation model for regional climate simulations over Europe. J Geophys Res 95(D11):18413-18431

Haugen JE, Haakensatd H (2006) Validation of HIRHAM version 2 with 50 and $25 \mathrm{~km}$ resolution. RegClim general technical report, no. 9, pp 159-173, http://regclim.met. no/results/gtr9.pdf

> Haylock MR, Hofstra N, Klein Tank AMG, Klok EJ, Jones PD, New M (2008) A European daily high-resolution gridded dataset of surface temperature and precipitation. J Geophys Res 113:D20119, doi:10.1029/2008JD10201

$>$ Jacob D (2001) A note to the simulation of the annual and interannual variability of the water budget over the Baltic Sea drainage basin. Meteorol Atmos Phys 77:61-73

Jacob D, Bärring L, Christensen OB, Christensen JH and others (2007) An intercomparison of regional climate models for Europe: model performance in present-day climate. Clim Change 81:31-52

Jung T, Miller MJ, Palmer TN, Towers P and others (2012) High-resolution global climate simulations with the ECMWF Model in Project Athena: experimental design, model climate, and seasonal forecast skill. J Clim 25: 3155-3172

Kjellström E, Bärring L, Gollvik S, Hansson U and others (2005) A 140-year simulation of European climate with the new version of the Rossby Centre regional atmospheric climate model (RCA3). Reports Meteorology and Climatology, 108, SMHI, Norrköping, Sweden

Knox JL, Hay JE (1985) Blocking signatures in the northern hemisphere: frequency distribution and interpretation. J Climatol 5:1-16

> Leduc M, Laprise R (2009) Regional climate model sensitivity to domain size. Clim Dyn 32:833-854

> Lucas-Picher P, Caya D, Biner S, Laprise R (2008) Quantification of the lateral boundary forcing of a regional climate model using an aging tracer. Mon Weather Rev 136:4980-4996

Lupo AR, Smith PJ (1995) Climatological features of blocking anticyclones in the northern hemisphere. Tellus 47A: 439-456

Matsueda M, Mizuta R, Kusunoki S (2009) Future change in wintertime atmospheric blocking simulated using a 20$\mathrm{km}$ mesh atmospheric global circulation model. J Geophys Res 114:D12114, doi:10.1029/2009JD011919

Pelly J, Hoskins B (2003) How well does the ECMWF Ensemble Prediction System predict blocking? QJR Meteorol Soc 129:1683-1702

Plummer D, Caya D, Côté H, Frigon A and others (2006) Climate and climate change over North America as simulated by the Canadian regional climate model. J Clim 19: 3112-3132

Radu R, Déqué M, Somot S (2008) Spectral nudging in a spectral regional climate model. Tellus 60A:898-910

Randall DA, Wood RA, Bony S, Colman R and others (2007) Climate models and their evaluation. In: Solomon S, Qin D, Manning M, Chen Z and others (eds) Climate Change 2007: the physical science basis. Contribution of Working Group I to the fourth Assessment Report of the Intergovernmental Panel on Climate Change. Cambridge University Press, Cambridge

Rauscher SA, Coppola E, Piani C, Giorgi F (2010) Resolution effects on regional climate model simulations of seasonal precipitation over Europe. Clim Dyn 35:685-711

Rex DF (1950) Blocking action in the middle troposphere and its effects upon regional climate. II. The climatology of blocking action. Tellus 2:275-301

Rinke A, Marbaix P, Dethloff K (2004) Internal variability in Arctic regional climate simulations: case study for the SHEBA year. Clim Res 27:197-209

Sanchez E, Gallardo C, Gaertner MA, Arribas A, Castro M (2004) Future climate extreme events in the Mediterranean simulated by a regional climate model: a first approach. Global Planet Change 44:163-180

- Sanchez-Gomez E, Somot S, Déqué M (2009) Ability of an ensemble of regional climate models to reproduce the weather regimes during the period 1961-2000. Clim Dyn 33:723-736

Sausen R, König W, Sielmann F (1995) Analysis of blocking events observation and ECHAM model simulations. Tellus 47A:421-438

> Scaife AA, Woolings T, Knight J, Martin G, Hinton T (2010) Atmospheric blocking and mean biases in climate models. J Clim 23:6143-6152

> Scaife AA, Knight JR (2008) Ensemble simulations of the cold European winter of 2005-2006. QJR Meteorol Soc 134:1647-1659

Scaife AA, Copsey D, Gordon C, Harris C and others (2011) Improved Atlantic winter blocking in a climate model. Geophys Res Lett 38:L23703, doi:10.1029/2011GL049573

> Schwierz C, Croci-Maspoli M, Davies HC (2004) Perspicacious indicators of atmospheric blocking. Geophys Res Lett 31:L06125, doi:10.1029/2003GL019341

Stein O (2000) The variability of Atlantic-European blocking as derived from long SLP time series. Tellus 52A:225-236

Tibaldi S, Molteni F (1990) On the operational predictability of blocking. Tellus 42A:343-365

Tibaldi S, Tosi E, Navarra A, Pedulli L (1994) Northern and Southern Hemisphere seasonal variability of blocking frequency and predictability. Mon Weather Rev 122:1971-2003

Tibaldi S, D'Andrea F, Tosi E, Roeckner E (1997) Climatology of Northern Hemisphere blocking in the ECHAM model. Clim Dyn 13:649-666

Treidl RA, Birch EC, Sajecki P (1981) Blocking action in the Northern Hemisphere: a climatological study. AtmosOcean 19:1-23

Trigo R, Trigo I, DaCamara C, Osborn T (2004) Climate impact of the European winter blocking episodes from the NCEP/NCAR reanalysis. Clim Dyn 23:17-28

Tyrlis E, Hoskins BJ (2008a) Aspects of Northern Hemisphere atmospheric blocking climatology. J Atmos Sci 65:1638-1652

Tyrlis E, Hoskins BJ (2008b) The morphology of Northern Hemisphere blocking. J Atmos Sci 65:1653-1665

van Meijgaard E, van Ulft LH, van de Berg WG, Bosveld FC, van den Hurk BJJM, Lenderink G, Siebesma AP (2008) The KNMI regional atmospheric climate model RACMO, version 2.1. KNMI Technical Report 302. KNMI, De Bilt, www.knmi.nl/bibliotheek/knmipubTR/TR302.pdf

Vial J, Osborn TJ (2012) Assessment of atmosphere-ocean general circulation model simulations of winter Northern Hemisphere atmospheric blocking. Clim Dyn 39:95-112

> Watson JS, Colucci SJ (2002) Evaluation of ensemble predictions of blocking in the NCEP global spectral model. Mon Weather Rev 130:3008-3021

> Woollings $\mathrm{T}$, Charlton-Perez A, Ineson S, Marshall A, Masato G (2010) Associations between stratospheric variability and tropospheric blocking. J Geophys Res 115:D06108, doi:10.1029/2009JD012742 